\title{
ANALISIS RANCANGAN SELEKSI TALENT POOL DENGAN METODE ASSESSMENT CENTRE PADA TEAM LEADER GUNA MENDUKUNG TALENT MANAGEMENT PROGRAM DI PT. METRAPLASA JAKARTA
}

\author{
Dewi Ulfah Arini ${ }^{1}$, Robby Kharisma ${ }^{2}$, Khairunnisa ${ }^{3}$ \\ Universitas Pamulang, Banten \\ Email : dosen01628@unpam.ac.id ${ }^{1}$, dosen01841@unpam.ac.id ${ }^{2}$ \\ dosen00743@unpam.ac.id ${ }^{3}$
}

\begin{abstract}
ABSTRAK
Maraknya perkembangan online shop dengan competitor seperti elevania dan Shopee memberikan pembelajaran bagi perusahaan untuk memerhatikan talent yang mendukung visi dan misi organisasi. Proses penetapan talent mengacu kepada Kompetensi yang sudah tersusun dan terimplementasi dalam bentuk Talent pool ini menjadi program dari Talent Management. Dimana pada prosesnya, talent manajemen membutuhkan assessment center sebagai bentuk seleksi dan Mapping. Metode Assessment centre sebagai proses seleksi yang didalamnya terdapat simulasi mengenai kondisi kerja yaitu penyelesaian masalah, diskusi kelompok dan memainkan peran sebagai pihak atasan untuk mengetahui penyelesaian masalah yang berhubungan dengan tim kerja. Hasil yang didapat adalah dari sejumlah karyawan yang di assessment sebanyak 215 hanya mendapatkan 60 karyawan yang memiliki kapasitas kompetensi yang memadai sesuai ketentuan pekerjaan. Karena itu, sebanyak $28 \%$ yang menjadi talenta memenuhi ketentuan yang ditetapkan sebagai future leader dengan kategori A. Pada kompetensi, terdapat 15 kompetensi yang muncul, yang tertinggi adalah kompetensi layanan pelanggan sebesar $54 \%$, komunikasi sebesar $53 \%$, Creative and Innovation sebesar 32\%, Teamwork 53\%, Leadership 15\%, Managing Strategi 17\%.. Sedangkan untuk psikotes sendiri pada talenta di Perusahaan ini memiliki potensi berfikir yang tinggi yaitu dengan rentang kategori Rata-rata (IQ 100) dan Diatas rata-rata ( $I Q=120$ ). Dengan demikian team leader dapat dipetakan dalam kuadran yang sesuai Matrix Human Asset Value dalam penyusunan Talent Pool.
\end{abstract}

Kata Kunci : Talent Pool, Assessment Centre, Kompetensi

\section{ABSTRACT}

The rapid of online shops with competitors such as Elevenia and Shopee provides lessons for companies to pay attention to talents who support the organization's vision and mission. The talent determination process refers to the competencies that have been compiled and implemented in the form of a Talent pool, which is a program of Talent Management. Where in the process, talent management requires an assessment center as a form of selection and mapping. The Assessment center method as a selection process in which there is a simulation of working conditions, namely problem solving, group discussions and playing the role of a superior to solve problems related to the work team. The results obtained are from a number of employees who were assessed as many as 215 only 60 employees who have adequate competency capacity according to job requirements. Therefore, as many as $28 \%$ of those who become talents meet the requirements set as future leaders. Of the 15 competencies that emerged, the highest was customer service competence at 54\%, communication at $15 \%$, Creative and Innovation by 32\%, Teamwork at 53\%, Leadership 15\%, Managing Strategi 17\%. As for the psychological test it self on talents in this company, it has the potential to think high, namely the range of categories Average (IQ 100) and Above average $(I Q=120)$. Thus, team leaders can be mapped in the appropriate quadrant for the Human Asset Value matrix in the preparation of the Talent Pool.

Keywords: Talent Pool, Assessment Centre, competence 


\section{PENDAHULUAN}

Penerapan Assessment centre sebagai proses rekrutment memiliki kriteria talenta yang perlu dimiliki. Standar yang dibutuhkan adalah manusia yang memiliki daya saing, jiwa kepemimpinan, pemahaman strategi market dan inovatif serta kemauan untuk mengembangkan organisasi dengan karakteristik BUMN didalamnya. Mengingat perusahaan PT Metraplasa memiliki sektor dibidang online retail yang menginduk pada nilai-nilai dan kompetensi yang mengacu pada perusahan Telekomunikasi. Oleh sebab itu, pengukuran yang dilakukan pun diselaraskan dengan kompetensi Induk, alat test yang dilakukan tidak hanya memiliki standar yang sejenis namun target yang ditetapkan sama guna mendapatkan talent-talent yang selaras. Kendalanya saat ini, talenta internal yang diajukan oleh atasan belum sepenuhnya memiliki kualifikasi yang sejalan dengan kriteria Seleksi talent pool. Oleh karena, Seorang talenta yang high potensial sudah pasti adalah high performa, namun high performa belum tentu high potential.

Berdasarkan jumlah 215 karyawan di perusahaan Metraplasa, sudah dilakukan proses Assesment pada sebaran jabatan pada tabel di bawah ini:

Tabel 1. Sebaran jabatan dalam proses Assessment Center

\begin{tabular}{lll}
\hline No & Departemen & Jumlah Karyawan \\
\hline 1 & Bussines Analyst & 3 \\
2 & Bussines Operation & 29 \\
3 & Bussiness Support \& IT & 9 \\
4 & Category Management & 34 \\
5 & Finance & 20 \\
6 & HCGA & 10 \\
7 & Legal & 2 \\
8 & Marketing & 46 \\
9 & Performance Management & 2 \\
10 & Platform Development & 57 \\
11 & Public Relation & 3 \\
\hline
\end{tabular}

Sumber: Data penelitian, 2020

Dari sebaran jabatan diatas penulis mengambil setidaknya yang memiliki potensi dengan kriteria Talent Pool hanya sebesar $28 \%$, artinya yang berada pada posisi Leader. Talent pool yang dimaksud merupakan pemetaan talent dengan mencari dan menempatkan sumber tenaga kerja berkualified juga mencari calon-calon pemimpin yang dapat menempati posisi yang kosong dan berperan pemimpin guna mendukung berjalannya visi misi serta tujuan dari organisasi. PT. Metraplasa yang memiliki 3P sebagai value yang harus diterjemahkan oleh setiap individu menjadi unjuk kerja dan meningkatkan performa organisasi internal dan eksternal, yaitu Pride, Progresvie dan Priority. Artinya

PT. Metraplasa memiliki bisnis utama adalah e-commerce memiliki divisi Platform Development, Content Marketing, Web Designer, Customer Services, Human Resource, IT Infrastructure, Business - Sales and Marketing, General Affairs dalam menjalankan proses bisnis dengan perubahan yang sangat cepat dan dinamis sehingga perlu menyelaraskan diri pada situasi yang tetap mengacu pada kualitas, professional dan mengutamakan project-project dari Induk untuk segera ditindaklanjut. 
Program seleksi melalui Assessment center tidak akan berhasil dan memiliki nilai bagi organisasi dan karyawan jika tidak menyusun talent pool yang efektif sebagai acuan dalam menciptakan talenta tanpa program yang efektif dan pola pemeliharaan talenta yang optimal".

\section{LANDASAN TEORI}

Dalam Menyusun program manajemen talenta pada suatu organisasi, maka disusunlah rancangan seleksi talent pool (peta talenta). Dimana organisasi menentukan jabatan yang menjadi key point yang akan dipetakan dalam Human Asset Value Matrix. Terdapat jabatan yang memiliki kontribusi bahwa perkembangan bisnis akan turun Ketika jabatan diisi oleh orang yang salah, yaitu Marcomm, B2B Category Manager, Platform Developer, QA Analyst dan UI-UX, Backend Developer, Frontend Developer serta Costumer Service. Jabatan inilah yang menjadi pengembang bisnis sehingga sangat dibutuhkan orang-orang yang memiliki kompetensi. Adapun kompetensi yang ditetapkan mengacu pada kompetenesi dari Telkom selaku induk organisasi dan disesuaikan dengan proses bisnis, Visi dan misi organisasi. Oleh karena itu terbagi 2 kategori yaitu : Professionla Kompetensi dan Leadership Kompetensi.

Tabel 2. Tabel Kompetensi

\begin{tabular}{cc}
\hline Profesional Kompetensi & Leadership Kompetensi \\
\hline 1. Conceptual Thinking & 1. Change Leadership \\
2. Organization Awareness & 2. Creative and Innovation \\
3. Concern for Order & 3. Costumer Service \\
4. Teamwork & 4. Decision Making \\
5. Impact Influencing & 5. Developing Other
\end{tabular}

Sumber: Data penelitian, 2020

Menurut Pella dan Inayati dalam buku manajemen talenta, peta talenta (talent pool) adalah proses menempatkan posisi setiap individu dalam perusahaan sesuai dengan keahlian, kompetensi, dan kapabilitas dalam sebuah peta dengan metode Human Asset Value Matrix [1]. Human Asset Value Matrix adalah suatu metode yang dapat digunakan perusahaan untuk meletakkan posisi karyawan dalam peta talenta. Dengan menggunakan metode penilaian prestasi (performance) dan potensi (potential), perusahaan dapat membuat matriks posisi karyawan berdasarkan nilai kinerja dan kompetensinya. Matrik HAV paling umum adalah Matriks $3 \times 3$, dengan 9 kuadran yang dapat membedakan pegawai dalam sembilan kategori. Human Asset Value Matrix dapat dilihat pada tabel dibawah ini:

Tabel 3. Sembilan Kuadran Kinerja (HAV)

\begin{tabular}{l|l|lll}
\hline \multirow{3}{*}{ Potensi } & Tinggi & Prolem Employee & Promising & Star Player \\
& Sedang & Doubtfull & Mediocre & Career Persona \\
& Rendah & Deadwood & Nice to Have & Best Fit \\
\cline { 3 - 5 } & & Rendah & Sedang & Tinggi \\
\hline \multicolumn{4}{c}{ Kompetensi Kinerja } & \\
\hline
\end{tabular}

Sumber: Pela \& Inayah, 2011 
Pada penilaian seleksi yang dilakukan adalah menggunakan metode Assessment centre yang menjadi salahsatu dasar dalam proses seleksi pemetaan talenta didalam organisasi. Menurut R. Dennis Middlemist, Michael A. Hitt, Charles R. Greer menyatakan bahwa : "Sebuah proses seleksi telah berevolusi dengan mengkombinasikan banyak perangkat seleksi lain seperti wawancara, prosedur pengujian yang bervariasi dan latihan - latihan yang dikembangkan untuk situasi tertentu yang mensimulasikan aspek - aspek tertentu dari pekerjaan dengan melihat pada kompetensi [2]. Hal tersebut mengacu bahwa perilaku yang pernah ditunjukkan dan sangat baik untuk memprediksi kemampuan yang bersangkutan di masa yang akan datang di tempat kerjanya. Menurut Spencer \& Spencer mengatakan ada 5 (lima) karakteristik kompetensi yaitu [3]:

1. Knowledge adalah informasi yang dimiliki seseorang dalam bidang tertentu.

2. Skill merupakan kemampuan untuk melaksanakan tugas mental atau tugas fisik tertentu. Skill merupakan karakteristik kompetensi yang berupa "action". Skill mewujudkan sebagai perilaku yang didalamnya terdapat motives, traits, self concept, dan knowledge.

3. Motivasi adalah sesuatu yang selalu dipikirkan atau di-inginkan seseorang yang dapat mengarahkan, mendorong atau menyebabkan orang melakukan suatu tindakan. Motif ini mengarahkan seseorang untuk menentukan atau menetapkan tindakan-tindakan yang memastikan dirinya mencapai tujuan yang diharapkan.

4. Traits, merujuk pada ciri bawaan yang bersifat fisik (physical characteristics) dan tanggapan yang konsisten terhadap berbagai situasi atau informasi.

5. Self concept yakni sikap, nilai atau image yang dimiliki seseorang tentang dirinya sendiri. Self concept ini akan memberikan keyakinan pada seseorang siapa dirinya. Apakah ia seorang percaya diri ataukah orang yang tidak percaya diri. Demikian pula apakah ia seseorang yang sabar ataukah ia selalu mengalami kesulitan dalam mengendalikan emosi.

Berdasarkan pada informasi diatas maka dapat disimpulkan bahwa penilaian Assessment centre dengan melihat kriteria baik dari kemampuan kerja atau ketrampilan pekerja, pengetahuan kerja dan sikap kerja dimana terdiri dari kemampuan mengelola tugas dan orang sehingga dapat menjadi pemimpin masa depan dengan menyesuaikan diri terhadap visi, misi dan strategi organisasi.

Tidak hanya melakukan seleksi dengan menggunakan kompetensi akan tetap juga menggunakan potensi dari hasil psikologi test sehingga menjadi salah satu bagian dalam penilaian penentukan peta talenta. Potensi menurut Harras, et al., adalah prediksi mengenai banyaknya tingkatan atau level (organisasi atau pekerjaan) dalam organisasi yang bisa dicapai oleh seorang karyawan berdasarkan hasil penilaian karyanya di waktu lalu maupun saat ini, kebutuhan pelatihan dan pengembangan, kemungkinan karier yang bisa di tempuh, dan level kompetensinya saat ini dan yang diperkirakan di waktu mendatang [4].

Pada penilaian seleksi menggunakan metode Assessment centre diharapkan dapat mewakili setiap individu dalam organsiasi untuk memaksimalkan seluruh kompetensi yang dimiliki dalam menjawab tantangan organisasi [5]. Hal ini karena, pada prosesnya terdapat simulasi-simulasi yang mencerminkan kondisi organisasi 
yang Beragam. Hal ini karena metode Assement centre menggunakan Multi Simulation, Multi Observer, Multi Ratter sehingga hasil yang didapatkan obyektif, tepat dan akurat $[6,7]$.

Sumber daya manusia adalah satu topik yang paling disoroti didalam organisasi karena roda perusahaan berkembang sesuai dengan tujuan mengacu kepada kekuatan, kualtas dan performa dari personil yang mengerjakan dan mendukung $[8,9]$. Oleh karena itu, perlu metode pengembangan sumberdaya manusa yang diyakini baik sehingga biaya organisasi dalam mengelola dan mengembangkan SDM dapat optimal dan tepat sasaran. Hasil 50 studi kehandalan terhadap metode AC mengindikasikan bahwa performa dan kesuksesan lebih baik dibandingkan dengan tools lainnya. Pada penelitian ang dilakukan Smith, Greggs dan Andrews [10,11] sebagai berikut:

Tabel 4. Hasil Pengukuran Validity AC

\begin{tabular}{ll}
\hline Teknik Pengukuran & Validity \\
\hline Assessment Centers ( Promotion ) & 0.63 \\
Work Sample Test & 0.55 \\
Ability Tests & 0.53 \\
Personality Test (Combines) & 0.41 \\
Research Bio-data & 0.38 \\
Sturcture Interviews & 0.31 \\
Typical Industry Interview & 0.15 \\
References & 0.13 \\
\hline
\end{tabular}

Sumber : Adiawaty, 2016

\section{METODOLOGI PENELITIAN}

Metode Penelitian menggunakan Metode Asessment Center dengan total populasi Team Leader di Perusahaan Metraplasa dengan berbagai departemen dan unit yang sudah dilakukan Assessment berjumlah 215 orang. Peneliti menentukan sampel penelitian dengan target sesuai dengan jumlah responden yaitu 60 peserta. Dengan kualifikasi adalah peserta yang masih eksisting didalam lingkup organisasi sejumlah 60 orang. Sumber Daya Manusia yang terbaik adalah sumberdaya manusia yang memiliki kelebihan yang akan menjadi pemimpin masa depan suatu perusahaan atau yang biasa disebut talenta. Berikut level jabatan yang ada di tahun 2020:

Tabel 5. Level Jabatan pada setiap unit kerja

\begin{tabular}{lll}
\hline No & Departemen & Jumlah Karyawan \\
\hline 1 & Bussines Analyst & 3 \\
2 & Bussines Operation & 29 \\
3 & Bussiness Support \& IT & 9 \\
4 & Category Management & 34 \\
5 & Finance & 20 \\
6 & HCGA & 10 \\
7 & Legal & 2 \\
8 & Marketing & 46 \\
9 & Performance Management & 2 \\
10 & Platform Development & 57 \\
11 & Public Relation & 3 \\
\hline
\end{tabular}

Sumber: Data penelitian, 2020 
Pengumpulan data dalam penelitian ini dilakukan selama 7 Bulan dari bulan Januari-Juli 2020 dengan menggunakan data primer dan data sekunder. Data primer diperoleh melalui pengamatan langsung di perusahaan dengan cara wawancara pada pihak perusahaan yang terkait dengan sumber daya manusia dan hasil pengujian Assessment Centre yang sudah dilaksanakan dalam waktu tertentu.

Sedangkan data sekunder diperoleh melalui sumber-sumber lain seperti buku, teori, literatur, yang berkaitan dan bermanfaat untuk mendukung penelitian. Data sekunder mencakup gambaran umum perusahaan, data tentang sejarah dan perkembangan perusahaan, struktur organisasi perusahaan, tenaga kerja, penilaian kinerja dan pengembangan induvidu karyawan yang diperoleh dari literatur serta laporan-laporan perusahaan. Metode yang digunakan dalam mengumpulkan data primer yaitu:

1. Wawancara Terstruktur

Wawancara merupakan suatu bentuk komunikasi langsung yang berupa tanya jawab dengan pihak yang berhubungan dengan penelitian ini. Tahapan wawancara dengan menggunakan kompetens dari hasil pengalaman yang sudah pernah dilakukan sebelumnya. Proses wawancara ini dilakukan untuk memperoleh gambaran dan penjelasan mengenai masalah yang diteliti. Wawancara yang dilakukan di PT Metraplasa (blanja,com) ini adalah dengan melalui tanya jawab terhadap pihak-pihak terkait, yaitu kepala masing-masing departemen di direktorat produksi dan kepala di di departemen sumnberdaya manusia.

2. Hasil Assessment Centre

Hasil Assessment centre yang sudah dilakukan sudah menunjukkan kompetensi para perserta yang diujikan sesuai pencapaian yang sudah dilakukan dan menjadi dasar serta landasan HC untuk melakukan proses promosi jabatan atau kenaikan tingkat. Sedangkan selain itu, hasil dari proses Assesment ini belum sepenuhnya digunakan secara maksimal dalam menentukan Future Leader di lingkup kerja IT. Dimana dalam proses Assessment diberikan suatu simulasi yang mencerminkan proses bisnis bidang e-commerce dengan mengkondisikan adanya tantangan, kendala dan target yang perlu dilakukan oleh setiap peserta. Sedangkan data sekunder diperoleh dengan cara sebagai berikut:

a. Studi kepustakaan

Studi kepustakaan dilakukan dengan mempelajari dan menelaah literaturliteratur berupa dokumen dan buku-buku teori yang relevan yang berhubungan dengan teori yang dibahas.

b. Berbagai laporan instansi

Laporan instansi baik berupa dokumen, laporan maupun catatan tertulis yang berhubungan dengan topik yang diteliti khususnya.

Data yang diperoleh akan dianalisis secara kualitatif dan kuantitatif. Data yang diperoleh melalui wawancara akan dianalisis secara kualitatif yang akan disajikan dalam bentuk uraian deskriptif. Sedangkan kuesioner akan dianalisis secara kuantitatif 


\section{Hasil Penelitian dan Pembahasan}

Perhitungan nilai total potensi diawal dengan menentukan bobot masing-masing indikatir pada soft competenis dan hard competensi. Selanjutnya dilakukan perhituangan untuk memperoleh skor masing-masing berdasarkan level target prasyarat dan level maksimum pada indikatir setiap jabatan dengan rumus :

\section{Skor $=$ Target Pencapaian $/$ Target Maksimum skor x $100 \%$}

Setelah mendapatkan skor masing-maisng indikator, dilakukan perhitungan untuk memperoleh nilai masing-masing indikayor dengan mengalikan bobor dengan skor. Kemudian setelah masing-masing indicator telah memiliki nilai, dilakukan penjumlagan kedua kategiru dengan memeprtimbangkan bobot yang masing-masing sebesar $50 \%$ berdasarkan ketetapan perusahaan dengan rumus sebagai berikut :

Total Nilai Potensi $=50 \% \times$ total nilai soft kompetensi $+50 \% \times$ Nilai Hard Kompetensi

Tabel 6. Hasil dari pengolahan data kriteria potensi

\begin{tabular}{|c|c|c|c|}
\hline \multicolumn{4}{|c|}{ Hard Competensies ( bobot $50 \%$ ) } \\
\hline Kompetensi & Target & Nilai & $\begin{array}{l}\text { Persentase } \\
\text { Nilai Peserta }\end{array}$ \\
\hline Costumer Service Orientation & 3 & 1,192 & $54 \%$ \\
\hline Creative and innovation & 3 & 1,32 & $32 \%$ \\
\hline Execution Focused & 3 & 1,61 & $14 \%$ \\
\hline \multicolumn{4}{|c|}{ Soft Competenisen (bobot $50 \%$ ) } \\
\hline Leadership & 3 & 1,33 & $15 \%$ \\
\hline Teamwork & 3 & 1,57 & $35 \%$ \\
\hline Communication & 3 & 1,56 & $32 \%$ \\
\hline Managing Strategi & 3 & 1,16 & $17 \%$ \\
\hline
\end{tabular}

Sumber: Data penelitian, 2020

Hasil pemetaan pengolahan data yang diperoleh dari peniaian assment kompetensi berdasarkan pada penilaian Assessment Centre antara level eksisting dengan jumlah skala yang digunakan dalam HAV Matrix yaitu 5 skala. Dari masingmasing jabatan diperoleh nilai yang menjadi masukan dalam pemetaan talent key position berupa nilai potensi dan kinerja setiap peserta yang melakukan proses assessment. Nilai dihasilkan setelah dilakukan dan menetapkan hasil kompetensi pada setiap jabatan. Nilai tersebut juga dikombinasikan dengan nilai potensi yang diberikan kepada peserta (asesi) sehingga dapat diketahui ketercapaian dan peta talent matrix sesuai dengan HAV-nya.

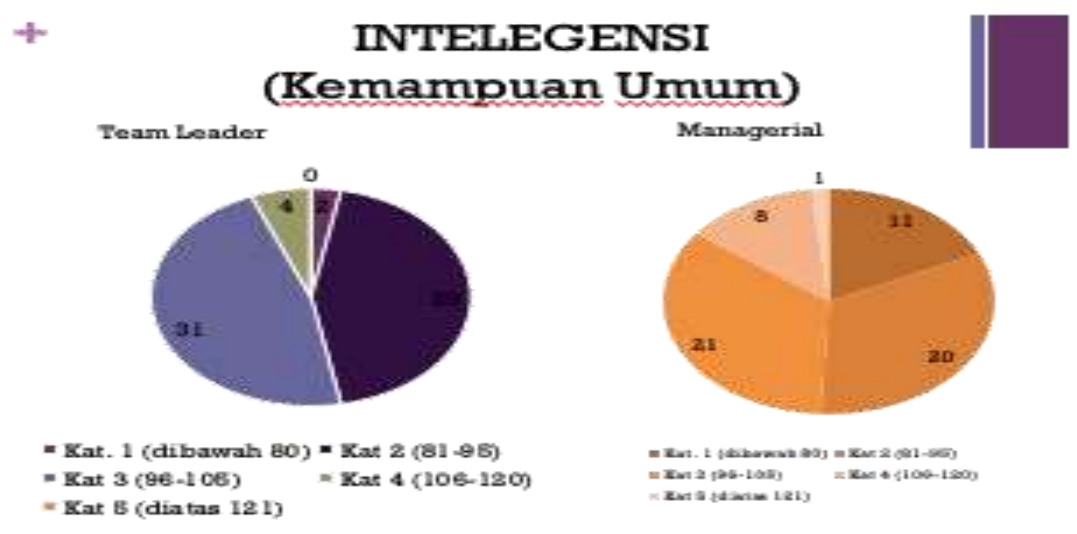

Gambar 1. Hasil Potensi level fungsional dan Managerial 


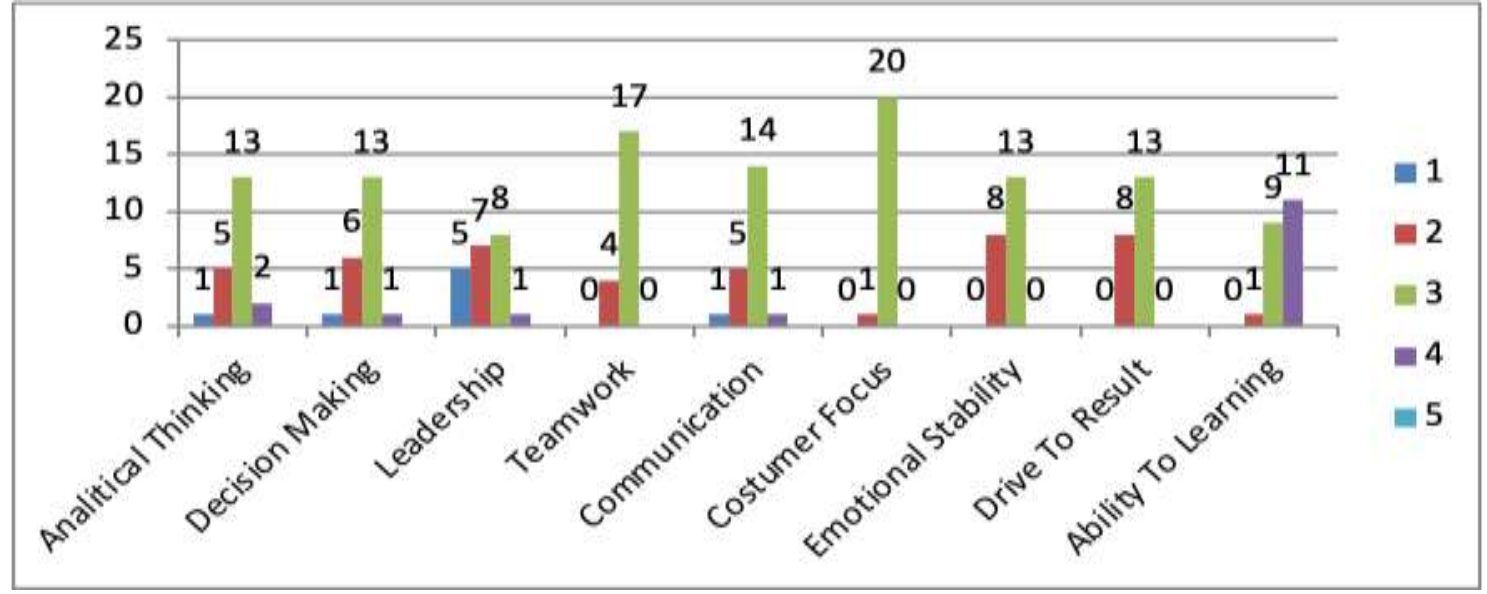

\section{Gambar 2 : Kompetensi Level Fungsional dan Manajerial}

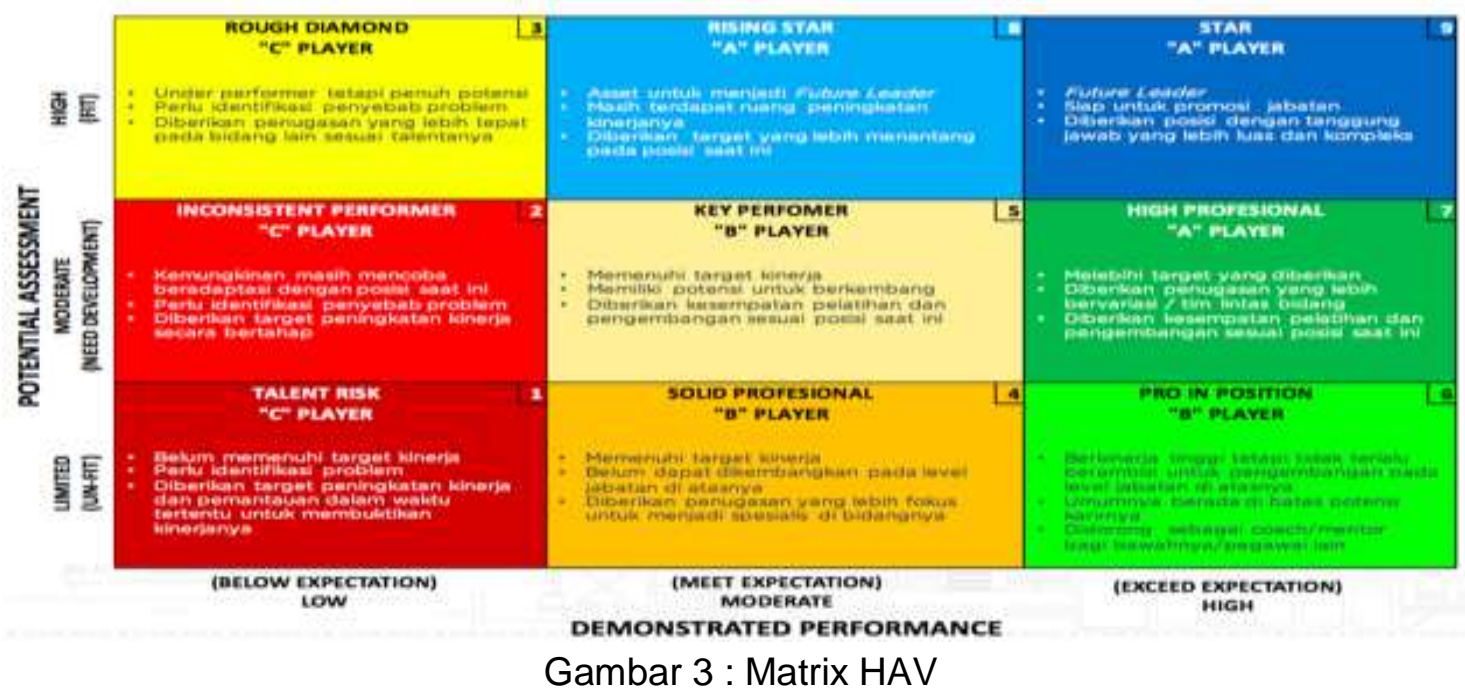

Berdasarkan hasil komparasi antara Total Potensi dan Kompetensi dari seleksi pada para Team leader dengan menggunakan Teknik Assessment centre maka menghasilkan data sebagai berikut :

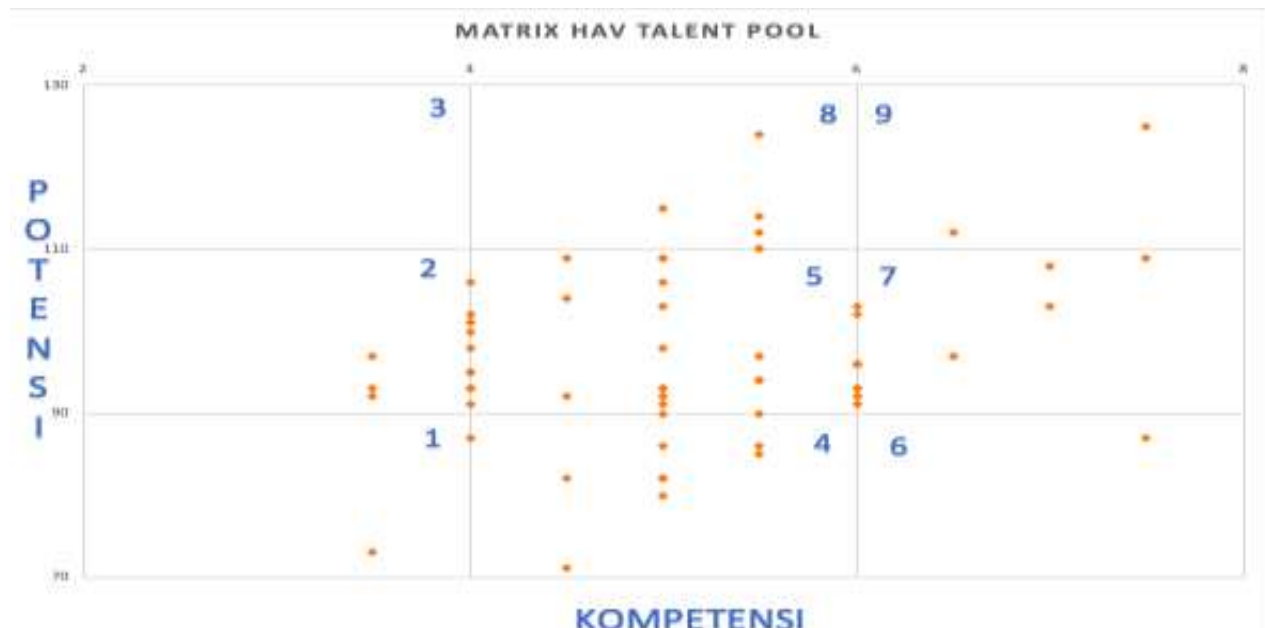

Gambar 4 : Sebaran Peserta Asesi sesuai dengan kuandran HAV 
Dari keseluruhan peserta yang dilakukan assessmen terdapat sebaran yang cukup luas dimana terdapat 2 peserta yang terjaring pada Kategori STAR yang sudah siap sebagai Future Leader, selain itu pada Quadran 7 yaitu High Profesional karena pengalaman dan wawasn yang dimliki sebelumnya pada perusahaan sejenis dengan kualifikasi kerja dan target yang sama. Oleh sebab itu, perusahaan telah memiliki calon Future Leader yang sudah terasah diperusahaan sebelumnya. Begitupula dengan Peserta yang masuk dalam Quadran 5, dimana sudah memiliki potensi yang berkembang baik dan perusahaan cukup mengoptimalkan dari sisi potensi dengan mentoring sehingga dapat mencapat strategi yang ditetapkan organsiasi dimasa mendatang [12]. Hal ini dapat dilihat dengan table dibawah ini :

Tabel 7. Tabel Sebaran Matrik HAV Team Leader pada Skor Talent Pool

\begin{tabular}{|c|c|c|c|c|c|}
\hline Quadran & $\begin{array}{l}\text { Klasifikasi } \\
\text { Talent }\end{array}$ & $\begin{array}{c}\text { Jumlah } \\
\text { Talent }\end{array}$ & $\begin{array}{l}\text { \% jumlah } \\
\text { karyawan }\end{array}$ & Kategori & Keterangan \\
\hline 9 & A & 2 & $3 \%$ & STAR & $\begin{array}{l}\text { Future Leader dan } \\
\text { Siap Promosi }\end{array}$ \\
\hline 8 & $A$ & 5 & $8 \%$ & RISING STAR & $\begin{array}{l}\text { Siap menjadi Future } \\
\text { Leader }\end{array}$ \\
\hline 7 & $A$ & 13 & $22 \%$ & $\begin{array}{c}\text { HIGH } \\
\text { PROFESIONAL }\end{array}$ & $\begin{array}{l}\text { Melebihi Target dan } \\
\text { Asset Future Leader }\end{array}$ \\
\hline 6 & B & 1 & $2 \%$ & $\begin{array}{l}\text { PRO IN } \\
\text { POSITION }\end{array}$ & $\begin{array}{l}\text { Berkinerja } \quad \text { Tinggi, } \\
\text { Sesuai sebagai } \\
\text { Coach atau Mentor }\end{array}$ \\
\hline 5 & B & 24 & $40 \%$ & $\begin{array}{c}\text { KEY } \\
\text { PERFORMER }\end{array}$ & $\begin{array}{l}\text { Memenuhi target dan } \\
\text { potensi berkembang }\end{array}$ \\
\hline 4 & B & 8 & $13 \%$ & $\begin{array}{c}\text { SOLID } \\
\text { PROFESIONAL }\end{array}$ & $\begin{array}{ll}\text { Memenuhi } & \text { Target } \\
\text { Kinerja dan } & \text { Belum } \\
\text { dikembangkan } & \\
\text { sebagau } & \text { Future } \\
\text { Leader } & \end{array}$ \\
\hline 3 & C & 0 & $0 \%$ & $\begin{array}{l}\text { ROUGH } \\
\text { DIAMOND }\end{array}$ & $\begin{array}{l}\text { Potensial namun } \\
\text { Under Performer, } \\
\text { Membutuhkan } \\
\text { coaching } \\
\text { counseling }\end{array}$ \\
\hline 2 & C & 6 & $10 \%$ & $\begin{array}{l}\text { INCONSISTENT } \\
\text { PERFOMER }\end{array}$ & $\begin{array}{l}\text { Kemungkinan } \\
\text { Karyawan baru dan } \\
\text { Fresh Graduate. }\end{array}$ \\
\hline 1 & C & 2 & $3 \%$ & TALENT RISK & $\begin{array}{l}\text { Karyawan } \\
\text { deadwood, kinerja } \\
\text { rendah dan tidak } \\
\text { bisa diandalkan }\end{array}$ \\
\hline
\end{tabular}

Sumber: Data penelitian, 2020

Berdasarkan hasil tabel analisa diatas, bahwa nilai potensi dan kompetensi hasil assessment pada pemetaan jabatan team leader diketahui sesuai dengan kuadran HAV dan pemetaan key position didalam organisasi. Hasil pemetaan pada HAV Matrix menunjukkan bahwa profile kategori Star yang termasuk dalam kategori yang akan dilakukan pengembangan secara cepat sebanyak 3\% dimana ada 2 personil yang siap mendapatkan promosi jabatan yang cukup strategis. Terdapat $8 \%$ untuk posisi Rising 
Star dimana 5 orang siap menjadi future leader sehingga organisasi perlu memberikan ruang untuk meningkatan kinerjanya. Kemudian, pada High Profesional terdapat 22\% dari total karyawan yang dilakukan assement dimana perlu adanya penugasan yang lebih bervariasi baik didalam unit dan lintas bidang agar produktivitas dapat meningkat. Pada kategori Pro in position terdapat $2 \%$ dimana terdapat personil yang berada pada posisi tersebut. Pada kategori Key Performer terdapat $40 \%$ dari total peserta yang melakukan Assessment dimana personil sudah memenuhi target dan berpotensi untuk dikembangkan hanya saja perlu ada pelatihan yang dapat mendukung kinerja dan pengembangan sesuai posisi saat ini, Pada Kategori selanjutanya dalah Solid Profesional terdapat $13 \%$ dimana tidak adanya personil pada posisi ii dan sudah sesuai dengan spesifikasi tugasnya. Selanjutnya, untuk Rough Diamond terdapat 0\% personil dimana tidak adanya performa yang menurun dan peru diberikan coaching dan counseling terhadap kendala dan masalahnya. Pada kategori Inkonsisten Performer terdapat $10 \%$ dimana adanya pengembangan usaha saat ini mengharuskan penerimaan karyawan pada kategori ini terdapat personil yang masih dibawah 6 bulan yang mengikuti program talent pool. Sedangkan kategori terakhir adalah Talent Risk dimana performa dan produktivitas yang rendah dan tidak bida diandalkan adalah $3 \%$ dimana peserta adalah karyawan lama yang sulit mengikuti perubahan dan perkembangan dan tuntutan dari jenis bisnis e-commerce sehingga sulit mengikuti target yang ditetapkan.

Dengan gambaran pada table tersebut, maka klasifikasi A dan B menjadi bagian dalam penentukan Pemetaan Talenta yang akan diberikan pengembangan secara skill dan knowledge serta attitude melalui Program Talent Manajemen dalam beberapa waktu sehingga dapat menempati posisi kunci dalam menempati jabatan yang ditetapkan. Oleh sebab itu, terdapat $50 \%$ karyawan terutama pada Departemen Platform Development dan Bisnis Alanis yang disesuaikan dengan program talent manajemen sehingga bisa mencapai tujuan yang ditetapkan.

\section{KESIMPULAN DAN SARAN}

Penerapan matrix Human Asset Value pada talent pool didasarkan pada tiga aspek yaitu Skill, Knowledge dan Attitude yang direpresentasikan pada Potensi, Kompetensi dan Sikap Kerja dengan nilai fitness kriteria untuk aspek potensi adalah $95 \%$ dan skor 60 pada jumlah total aspek kompetensi sebagai dasar menentukan talent pool.

Pendekatan seleksi menggunakan Metode Assessment Centre yang memiliki integrasi dengan berbagai simulasi kerja (Kepemimpinan, Bisnis proses dan Kasus Analisys) yang merepresentasikan posisi Future Leader. Sebaran Peserta berada pada Quadran 7 yaitu High Profesional, Sebagai calon Future Leader yang sudah terasah dari pengalaman. Peserta yang masuk dalam Quadran 5, sudah memiliki potensi dan kompetensi yang berkembang. Peserta Inkonsisten Performer (Quadran 2) adalah peserta yang Fresh Graduate dengan pengalaman yang minim namun masuk dalam program MT di PT. MP.

Peserta Quadran 1 adalah Peserta dengan kategori karyawan lama dan cenderung menjadi "penyakit" (Bad Influencer) didalam organisasi 


\section{DAFTAR PUSTAKA}

[1] Pella DA, \& Inayati A. 2011. Talent Management. Jakarta (ID) : PT. Gramedia Pustaka Utama

[2] Wahyudi, W. (2018). The Influence of Emotional Intelligence, Competence and Work Environment on Teacher Performance of SMP Kemala Bhayangkari Jakarta. SCIENTIFIC JOURNAL OF REFLECTION: Economic, Accounting, Management and Business, 1(2), 211-220.

[3] Vibriana, E. (2019). EFFECT OF PERSUASIVE ABILITY, TECHNICAL ABILITY AND WORK ETHICS OF FIELD EXTENSION STAFF (PPL) ON SATISFACTION OF BROILER CHICKEN BREEDERS AT PT. SIERAD PRODUCE. SCIENTIFIC JOURNAL OF REFLECTION : Economic, Accounting, Management and Business, 2(1), 11-20

[4] Harras, H., Sugiarti, E., \& Wahyudi, W. (2020). KAJIAN MANAJEMEN SUMBER DAYA MANUSIA UNTUK MAHASISWA.

[5] Mendo, A. Y., Asnawi, M. A., \& Kadullah, M. R. P. (2018). PENGARUH PENERAPAN ASSESSMENT CENTRE TERHADAP PRESTASI KERJA PADA KARYAWAN PT. BPR PARODANA GORONTALO. JAMBURA: Jurnal Ilmiah Manajemen dan Bisnis, 1(3), 392-403.

[6] Mulyasari, I. (2019). Pengaruh kecerdasan emosional dan kompetensi terhadap kinerja pegawai. Journal of Management Review, 2(2), 190-197.

[7] Sudiatmoko, S. (2018). STUDY OF PERFORMANCE ASSESSMENT EFFECTIVENESS ON HUMAN RESOURCES GOVERNMENT PUBLIC DEPARTMENT IN JAKARTA. SCIENTIFIC JOURNAL OF REFLECTION : Economic, Accounting, Management and Business, 1(3), 341-350

[8] Khan, Y., Hasan, A., \& Rasuli, M. (2018). FAKTOR-FAKTOR YANG MEMPENGARUHI KINERJA PEGAWAI DI BAGIAN ADMINISTRASI KUANGAN SEKRETARIAT DAERAH PROVINSI RIAU. Jurnal Akuntansi (Media Riset Akuntansi \& Keuangan), 7(1).

[9] Muizu, W. O. Z., Titisari, A., \& Sule, E. T. (2018). Peran Knowlege Sharing Terhadap Kinerja Pegawai Perusahaan Telekomunikasi. INOBIS: Jurnal Inovasi Bisnis dan Manajemen Indonesia, 1(3), 397-406.

[10] Adiawaty, S. (2016). Pengembangan Sumber Daya Manusia Unggul Melalui Assessment Center.

[11] Ramly, A. T. (2016). Pengembangan Sumber Daya Manusia yang Unggul Berbasis Pumping-HR Model. Jurnal Manajemen (Edisi Elektronik), 7(2), 138151.

[12] Anggraeni, F. N. (2020). DETERMINAN MOTIVASI INTERNAL TERHADAP KINERJA. SCIENTIFIC JOURNAL OF REFLECTION: Economic, Accounting, Management and Business, 3(2), 161-170. 